OPEN ACCESS

Edited by:

Jozsef Haller,

Institute of Experimental Medicine,

Hungary

Reviewed by: Juan M. Dominguez,

The University of Texas at Austin,

USA

Alexander G. Ophir, Cornell University, USA

*Correspondence:

Jon T. Sakata

jon.sakata@mcgill.ca

Received: 16 November 2015 Accepted: 24 May 2016

Published: 14 June 2016

Citation:

Toccalino DC, Sun H and Sakata JT

(2016) Social Memory Formation Rapidly and Differentially Affects the Motivation and Performance of Vocal

Communication Signals in the

Bengalese Finch (Lonchura striata

var. domestica).

Front. Behav. Neurosci. 10:113.

doi: 10.3389/fnbeh.2016.00113

\section{Social Memory Formation Rapidly and Differentially Affects the Motivation and Performance of Vocal Communication Signals in the Bengalese Finch (Lonchura striata var. domestica)}

\author{
Danielle C. Toccalino ${ }^{1}$, Herie Sun ${ }^{2}$ and Jon T. Sakata ${ }^{1,2,3 *}$ \\ ${ }^{1}$ Integrated Program in Neuroscience, McGill University, Montreal, QC, Canada, ${ }^{2}$ Department of Biology, McGill University, \\ Montreal, QC, Canada, ${ }^{3}$ Center for Research in Behavioral Neurobiology, Montreal, QC, Canada
}

Cognitive processes like the formation of social memories can shape the nature of social interactions between conspecifics. Male songbirds use vocal signals during courtship interactions with females, but the degree to which social memory and familiarity influences the likelihood and structure of male courtship song remains largely unknown. Using a habituation-dishabituation paradigm, we found that a single, brief $(<30 \mathrm{~s})$ exposure to a female led to the formation of a short-term memory for that female: adult male Bengalese finches were significantly less likely to produce courtship song to an individual female when re-exposed to her 5 min later (i.e., habituation). Familiarity also rapidly decreased the duration of courtship songs but did not affect other measures of song performance (e.g., song tempo and the stereotypy of syllable structure and sequencing). Consistent with a contribution of social memory to the decrease in courtship song with repeated exposures to the same female, the likelihood that male Bengalese finches produced courtship song increased when they were exposed to a different female (i.e., dishabituation). Three consecutive exposures to individual females also led to the formation of a longer-term memory that persisted over days. Specifically, when courtship song production was assessed 2 days after initial exposures to females, males produced fewer and shorter courtship songs to familiar females than to unfamiliar females. Measures of song performance, however, were not different between courtship songs produced to familiar and unfamiliar females. The formation of a longer-term memory for individual females seemed to require at least three exposures because males did not differentially produce courtship song to unfamiliar females and females that they had been exposed to only once or twice. Taken together, these data indicate that brief exposures to individual females led to the rapid formation and persistence of social memories and support the existence of distinct mechanisms underlying the motivation to produce and the performance of courtship song.

Keywords: directed song, birdsong, courtship, vocal performance, songbird 


\section{INTRODUCTION}

The expression of social behaviors is modulated by cognitive processes. In particular, social memory and familiarity can influence the expression of various forms of social behavior, including reproductive (Miller, 1979; O'Loghlen and Beecher, 1999; Ophir and Galef, 2004; Vignal et al., 2008; Griffith and Ejima, 2009; Iwasaki et al., 2013; Heinig et al., 2014), parental (McCabe and Horn, 1994; Horn, 2004; Town and McCabe, 2011), and aggressive behaviors (Stoddard et al., 1991; Temeles, 1994; Bradbury and Vehrencamp, 2011; Nishizawa et al., 2011; Grabowska-Zhang et al., 2012; Jaška et al., 2015). For example, in both mice and rats, the amount of time an individual spends investigating or vocalizing in response to another individual decreases as a function of familiarity (D’Amato, 1997; D’Amato and Moles, 2001; Moles et al., 2007; Musolf et al., 2010; Lukas et al., 2013; Perna et al., 2015). In socially monogamous voles, mating leads to the formation of a social memory for the mate which then affects mating, affiliative, and aggressive behaviors toward conspecifics (Young and Wang, 2004; Young et al., 2008; Blocker and Ophir, 2015). Additionally, across various species, females preferentially mate with males that they have observed to win aggressive interactions (Mennill et al., 2002; Ophir and Galef, 2004; White, 2004; Bradbury and Vehrencamp, 2011) or observed to have mated with other females ("mate copying": Schlupp et al., 1994; Valone and Templeton, 2002; Galef, 2008). As such, understanding the processes underlying memory formation and individual recognition are important for understanding mechanisms underlying the expression of social behaviors (Insel and Fernald, 2004).

While the influence of social memory on the likelihood of social behavioral expression is well established, we know relatively little about the degree to which distinct components of social behavior differentially reflect social memory or about the factors that influence the rapidity and persistence of social memory formation. For example, many studies have found that social memory formation affects the motivation to copulate with individual females (e.g., Wilson et al., 1963; Dewsbury, 1981; Johnston and Rasmussen, 1984; Tan et al., 2013; Schnell et al., 2014) but only a handful of studies have examined how familiarity could affect the performance of copulatory behaviors (e.g., Dewsbury, 1979; Riters and Balthazart, 1998). Males of many vertebrate species produce courtship signals to solicit copulation from females, and social memory could differentially affect the motivation and performance of courtship behaviors. For example, male Barbary doves produce more bowing displays when courting unfamiliar females than when courting familiar partners (Erickson and Morris, 1972), and male zebra finches produce more courtship songs to unfamiliar females (Caryl, 1976). However, the degree to which familiarity affects the stereotypy and intensity of such displays remains largely unknown.

Additionally, relatively little is known about how the amount of social interactions influences the rapidity and persistence of social memory formation. A number of studies have found that a single exposure to a conspecific can influence the nature of subsequent interactions with familiar individuals (e.g., Hilliard et al., 1997; D’Amato and Moles, 2001; Moles et al., 2007; Lukas et al., 2013; Perna et al., 2015). However, few studies directly examine how different amounts of social interactions affect distinct aspects of social behavior or the persistence of behavioral changes (e.g., Guan and Dluzen, 1994; Sakata et al., 2002). Understanding the degree to which responses to familiar individuals persist over hours to days is important because such persistence could reflect the longer-term consolidation of social memories.

Here we conducted a series of experiments to reveal how social memory formation affects the production and performance of courtship song in male Bengalese finches. Songbirds like the Bengalese finch have been critical for understanding mechanisms underlying the learning and control of social and communicative behaviors (Dong and Clayton, 2009; Bolhuis et al., 2010; Sakata and Vehrencamp, 2012; Brainard and Doupe, 2013; Bertram et al., 2014; Woolley and Kao, 2015). Male Bengalese finches are excellent for revealing the degree to which social memory formation differentially affects the motivation to produce and the performance of courtship song because they produce courtship songs to solicit copulations from females and alter various aspects of their song performance during courtship interactions (Sakata and Vehrencamp, 2012; Dunning et al., 2014; James and Sakata, 2015; Matheson et al., 2016). We hypothesized that exposures of males to females would rapidly affect the display of male courtship song, that the magnitude of the effect of familiarity would increase with more exposures to females, and that familiarity could differentially affect the motivation to produce and the performance of male courtship song.

\section{MATERIALS AND METHODS}

\section{Animals}

Adult male Bengalese finches ( $>4$ months; $n=16$ ) were raised in our colony at McGill University or purchased from vendors (Exotic Wings and Pet Things, Ontario, ON, Canada). Outside of experimental periods, males were housed in same-sex group cages and not able to see or hear stimulus females. Birds were housed on a 14L:10D light cycle and provided food and water ad libitum. All procedures were approved by the McGill University Animal Care and Use Committee and performed in accordance with guidelines of the Canadian Council on Animal Care.

\section{Behavioral Testing}

\section{General}

Beginning at least one day before experimentation, male Bengalese finches were housed individually in cages $(20 \times 20 \times 20 \mathrm{~cm})$ in sound-attenuating chambers ("soundboxes"; TRA Acoustics, Cornwall, Ontario, ON, Canada). For all experiments, we analyzed the production of courtship song by briefly exposing male Bengalese finches to individual females (Sakata et al., 2008; Sakata and Brainard, 2009; James and Sakata, 2015; Matheson et al., 2016). In brief, 
during experimental sessions, we exposed individual male Bengalese finches to a female housed in a separate cage and assessed whether he produced courtship song. The courtship songs of Bengalese finches are readily distinguishable from noncourtship songs and are generally associated with a male facing or approaching a female, performing a courtship dance (e.g., pivoting body from side to side), and fluffing his plumage (Morris, 1954; Zann, 1996). Behavior was remotely monitored by video camera, and only songs that were accompanied by at least two of the above behaviors were categorized as courtship songs. Male Bengalese finches produce courtship songs within seconds of the introduction of a stimulus female and can produce multiple courtship song bouts in rapid succession during each female presentation. For all experiments, females were removed after the termination of a male's courtship song or after $\sim 30 \mathrm{~s}$ if the male did not sing, and the interval between exposures to females was 4-5 min. Non-courtship song bouts are spontaneously produced when birds are alone and generally separated by seconds to minutes. Behavioral tests were conducted 2-6 h after lights came on.

All males were first screened for courtship vigor by exposing them to six different stimulus females. Only males that courted at least $50 \%$ of the females during these screening tests were included in experiments ( $n=16$ males).

\section{Effects of Familiarity on the Production and Performance of Courtship Song}

We investigated short- and longer-term effects of familiarity on courtship song performance. In general, we assessed the effect of familiarity on courtship song performance by consecutively exposing male Bengalese finches to individual females $1-3$ times. For " $3 \mathrm{X}$ tests" $(n=16)$ and " $2 \mathrm{X}$ tests" $(n=10)$, males were exposed to individual females three or two consecutive times, respectively, before changing the identity of the stimulus female (Figure 1). For "1X tests" $(n=13)$, male Bengalese finches were exposed to an individual female on only one occasion before changing the identity of the stimulus female (Figure 1). Males were exposed, on average, to 7.9 (range: 6-10) and 12.1 (range: 11-15) different stimulus females during $3 \mathrm{X}$ and $1 \mathrm{X}$ tests, respectively. All males were exposed to eight different stimulus females during $2 \mathrm{X}$ tests. We revealed short-term effects of familiarity by analyzing changes to the likelihood and acoustic structure of courtship song across consecutive exposures to stimulus females.

We also investigated the degree to which memories for individual females persisted over days and the effect of repeated female exposures on the formation of longer-term social memories. To this end, we analyzed the degree to which a random subset of the males given $3 \mathrm{X}(n=13), 2 \mathrm{X}(n=10)$, and $1 \mathrm{X}(n=7)$ tests produced courtship song to familiar and unfamiliar females 2 days after $3 \mathrm{X}, 2 \mathrm{X}$, and $1 \mathrm{X}$ tests. For these tests of longer-term memory ("longer-term memory tests"), we presented each experimental male with stimulus females that he had been exposed to 2 days earlier ("familiar females") and with females that he had not been exposed to 2 days

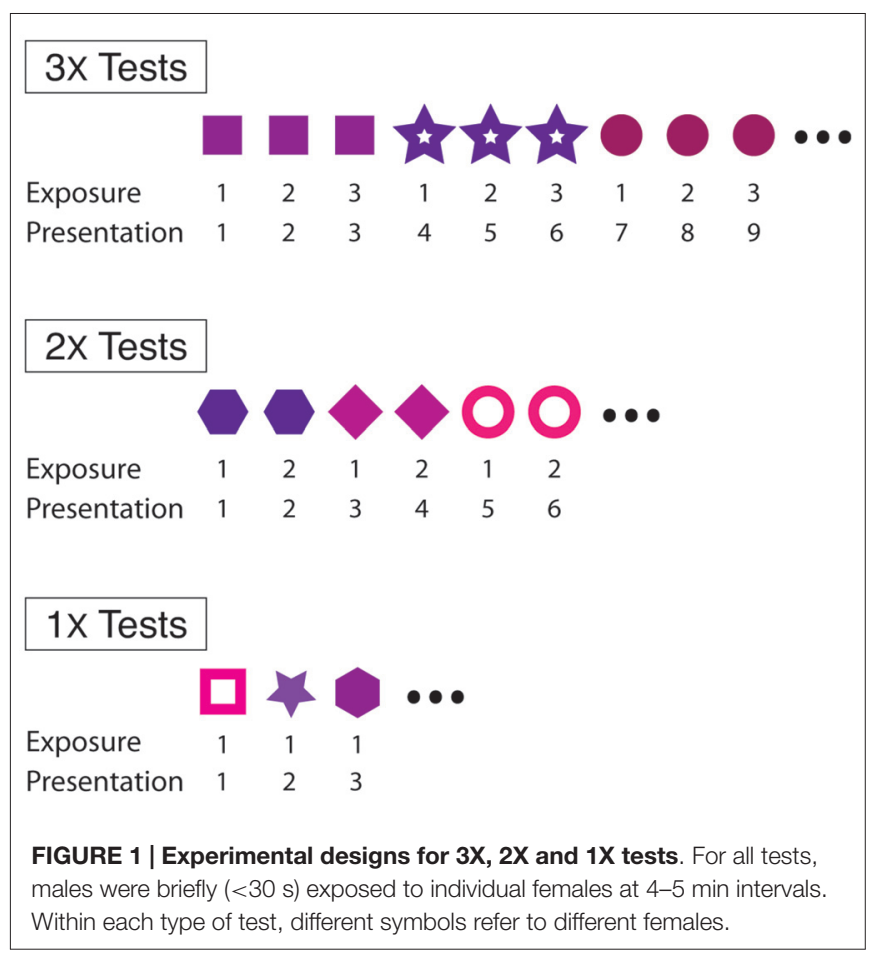

earlier ("unfamiliar females"). We used the testing protocol described above for $1 \mathrm{X}$ tests and exposed experimental males to individual stimulus females only once before changing the identity of the female. The order of female presentations was pseudo-randomized such that familiar and unfamiliar females were presented at comparable periods in the testing session (e.g., across all memory tests, median rank order for familiar and unfamiliar females was not different: $\left.F_{(1,29)}=0.1 ; p=0.7935\right)$. During longer-term memory tests following $3 \mathrm{X}$ and $1 \mathrm{X}$ tests, males were exposed, on average, to 16.0 (range: 12-20) and 18.6 (range: 12-24) stimulus females, respectively. During longerterm memory tests following $2 \mathrm{X}$ tests, all males were exposed to 16 stimulus females. Experimental males were exposed to the same number of familiar and unfamiliar females during longerterm memory tests for all but 2 out of 30 cases (in the outlying cases, males were exposed to $10-20 \%$ more novel females than familiar females).

All 16 males were administered $3 \mathrm{X}$ tests. In addition, random subsets of males were also administered $1 \mathrm{X}(n=6), 2 \mathrm{X}(n=3)$, or both $1 \mathrm{X}$ and $2 \mathrm{X}$ tests $(n=7)$ in conjunction with $3 \mathrm{X}$ tests. For those birds that were administered $3 \mathrm{X}$ and $1 \mathrm{X}$ tests ( $n=13$ ), the order of testing was randomized (five underwent $3 \mathrm{X}$ tests first, eight underwent $1 \mathrm{X}$ tests first). $2 \mathrm{X}$ tests were conducted in response to results from $3 \mathrm{X}$ and $1 \mathrm{X}$ tests and followed $3 \mathrm{X}$ and $1 \mathrm{X}$ tests. Tests were separated by a minimum of 2 months.

\section{Song Collection and Analysis}

For all tests, birds were housed individually in soundboxes, and song was recorded using an omnidirectional microphone (Countryman Associates, Inc., Menlo Park, CA, USA) positioned above the male's cage. A computerized, song-activated recording 
system was used to detect and digitize song (Sound Analysis Pro v.1.04: http://ofer.sci.ccny.cuny.edu/html/sound_analysis.html, digitized at $44.1 \mathrm{kHz}$ ). Recorded songs were digitally filtered (0.3-8 kHz) for off-line analysis using software custom-written in the Matlab programming language (The MathWorks, Natick, MA, USA).

We analyzed the courtship and non-courtship songs produced by male Bengalese finches during $3 \mathrm{X}$ tests to examine the effects of social context and familiarity on song performance. We analyzed the effect of social context by comparing courtship and non-courtship songs (e.g., Kao and Brainard, 2006; Sakata et al., 2008; Woolley et al., 2014; James and Sakata, 2015). Males were exposed to females at 4-5 min intervals, which allowed for the collection of non-courtship song between female exposures. However, not all birds produced renditions of non-courtship song between female presentations; therefore, non-courtship songs were also recorded for $30 \mathrm{~min}$ before and after testing sessions (e.g., Sakata et al., 2008; Sakata and Brainard, 2009; James and Sakata, 2015). To increase the reliability of our estimates of means and variances for each condition, we analyzed the effect of social context on song performance only in males that produced courtship song on more than three presentations of females and produced more than three non-courtship songs during the experimental period ( $n=14$ males).

We analyzed the effect of familiarity on song performance in two ways. First, we compared the structure of courtship songs produced during a male's first exposure to stimulus females to the structure of courtship songs produced during all subsequent exposures to those same females during $3 \mathrm{X}$ tests. To increase the reliability of our estimates of means and variances for each condition, we only analyzed songs from males that produced at least three songs during their first exposure to females and at least three songs during all subsequent exposures to females ( $n=12$ males). Second, we compared the acoustic structure of courtship songs produced to familiar and to unfamiliar females during longer-term memory tests that followed $3 \mathrm{X}$ tests. We analyzed only the songs of males that produced courtship song to at least three familiar and at least three unfamiliar females during these tests $(n=7$ males). For both of these analyses, we were particularly interested in testing the hypothesis that courtship songs become less distinct from non-courtship songs as females become more familiar.

We analyzed a variety of song features that are affected by social interactions and are salient to females, including syllable sequencing, song tempo, syllable structure, and song durations (Kao and Brainard, 2006; Sakata et al., 2008; Woolley and Doupe, 2008; Hampton et al., 2009; Sakata and Brainard, 2009; Dunning et al., 2014; Heinig et al., 2014; James and Sakata, 2015; Matheson et al., 2016). Bengalese finches produce bouts of song that consist of distinct acoustic elements ("syllables") arranged in both stereotyped and variable sequences. "Syllables" are individual acoustic elements that are separated from each other by $>5 \mathrm{~ms}$ of silence, and "song bouts" are contiguous segments of song that are separated from each other by $>500 \mathrm{~ms}$ of silence (Sakata et al., 2008).
Identical to previous studies, we manually labeled syllables based on visual inspection of spectrograms following amplitudebased syllable segmentation in Matlab (e.g., Sakata et al., 2008; Heinig et al., 2014; James and Sakata, 2014; Matheson et al., 2016). Song was labeled by two experts (HS and JTS) who were blind to the social context and the familiarity of stimulus females.

Bengalese finch song is characterized by nodes with variable sequencing called "branch points", and we analyzed changes to syllable sequencing at such branch points. Sequence variability at branch points is not simply biological noise but reflects a controlled aspect of song that is stable over days and weeks and modulated by social context (Okanoya and Yamaguchi, 1997; Sakata et al., 2008; Hampton et al., 2009; Warren et al., 2012; Heinig et al., 2014; James and Sakata, 2014, 2015; Matheson and Sakata, 2015a). We analyzed the probability of different syllable transitions at branch points (typically 2-5 distinct transitions per branch point), paying close attention to longerrange statistics in sequencing (Fujimoto et al., 2011; Warren et al., 2012; James and Sakata, 2014; Matheson et al., 2016). Stereotyped and branch point sequences were visually selected during manual labeling and confirmed using bigram plots (e.g., Okanoya and Yamaguchi, 1997; Kakishita et al., 2008; Fujimoto et al., 2011; Matheson et al., 2016). Sequences were considered to be branch points if the transition probability for any transition from that sequence was $<95 \%$ under any of the conditions being compared. We computed the transition entropy, a measure of variability, of each branch point using the following formula:

$$
\text { transition entropy }=\Sigma-p_{i} * \log _{2} p_{i}
$$

where, the sum is over all transitions produced at the branch point, and $p_{\mathrm{i}}$ is the probability of the ith transition across all renditions of the branch point. Transition entropy summarizes the variability of syllable sequencing: branch points with more variable and unpredictable transitions (i.e., closer to uniform probability) have higher transition entropy scores. Only branch points that occurred at least 10 times within each condition were included in the analysis. Instances in which song was terminated immediately following the branch point were not included in the calculation of entropy.

Changes to song tempo were analyzed using methods similar to previous studies (Cooper et al., 2012; James and Sakata, 2014, 2015). Specifically, we identified and measured the duration of a single, commonly produced sequence in an individual's song. Sequence durations were defined as the interval between the onset of the first syllable of the sequence to the onset of the last syllable of the sequence. Onsets were used to compute sequence durations because onsets are sharper and more consistent across renditions, leading to a more stable and reliable estimate of song tempo. Because sequence durations increase as the song progresses (Chi and Margoliash, 2001; Cooper and Goller, 2006; Glaze and Troyer, 2006) and because song durations can change as a function of social context and familiarity, we restricted our analysis to the first occurrence of the sequence in each 
song (e.g., James and Sakata, 2014, 2015; Matheson et al., 2016).

To analyze changes to syllable structure, we calculated the fundamental frequency (FF) of syllables that had distinct and stable harmonic structure. The FF of such syllables is tightly regulated by the nervous system and represents an important metric of song performance (Mooney, 2009; Sakata and Vehrencamp, 2012; Brainard and Doupe, 2013). To compute the FF, we calculated the autocorrelation of a segment of the sound waveform (8- or 16-ms window) and defined the FF as the distance, in $\mathrm{Hz}$, between the zero-offset peak and the highest peak in the autocorrelation function. To improve the resolution and accuracy of frequency estimates, we performed a parabolic interpolation of the peak of the autocorrelation function (de Cheveigné and Kawahara, 2002). Each rendition of a syllable was visually screened to ensure that we analyzed only examples devoid of sound artifacts that could affect FF calculations (e.g., sound of movement, female calls in background). Only syllables that occurred more than 10 times within each condition were included in the analysis. For each syllable, we computed the mean and variability of FF across renditions, two aspects that have been found to change across social contexts (e.g., Sakata et al., 2008; Hampton et al., 2009). We characterized the variability of FF across renditions using the coefficient of variation (CV: standard deviation/mean).

In addition to these features, we also analyzed contextand familiarity-dependent changes to the number of introductory notes preceding song onset and to song duration. Introductory notes are brief, low amplitude vocal elements with simple acoustic structure that are repeated consecutively before song onset. We counted introductory notes beginning with the first introductory note preceding the first song syllable, counting backwards until we reached $>500$ ms of silence (Sakata et al., 2008; Hampton et al., 2009; Matheson and Sakata, 2015a). We defined the duration of a song bout as the interval from the onset of the first syllable of the song bout to the offset of the last syllable of the song bout. Because males can rapidly produce multiple song bouts during a single presentation of a female, we calculated courtship song durations as the sum duration of all courtship song bouts produced during each female presentation.

\section{Statistical Analyses}

We analyzed the effect of familiarity on the production and performance of courtship song. To examine the effect of familiarity on the motivation to produce courtship song, we analyzed the proportion of presentations in which males produced courtship song. To analyze the short-term effects of familiarity on courtship song production, we analyzed the proportion of presentations during which males produced courtship song as a function of exposure number (e.g., 1st, 2nd, or 3rd exposures to individual stimulus females during $3 \mathrm{X}$ tests). To analyze longer-term effects of familiarity on the motivation to produce courtship song, we compared the proportion of presentations of familiar or unfamiliar females during which males produced courtship song. In addition to analyzing the effects of familiarity on the motivation to produce song, we also analyzed short- and longer-term effects of familiarity on measures of song performance (transition entropy of branch points, sequence durations, mean and $\mathrm{CV}$ of $\mathrm{FF}$, the number of introductory notes preceding song, and song durations) as well as context-dependent changes to these features.

All data were analyzed using mixed effects models. For example, in our analysis of changes to the likelihood of courtship song across consecutive exposures to females, the proportion of presentations in which a male produced courtship song was the dependent variable, exposure number (1st, 2nd, or 3rd) was the independent variable, and bird ID was a random variable (repeated-measures analysis; Gotelli and Ellison, 2013). We confirmed that sphericity was not violated before running these models (Mauchly criterion, $\alpha=0.05$ ). Similar mixed effects models were used to assess differences in the likelihood of courtship song production during tests for longer-term memory (e.g., 2 days after $3 \mathrm{X}$ tests) as well as differences in measures of song performance between non-courtship and courtship songs, between courtship songs produced during the first and subsequent exposures to females, and between courtship songs produced to familiar and unfamiliar females. Because we measured sequence variability (transition entropy) at multiple branch points and the FF of multiple syllables per bird, we also included branch point ID nested within bird ID or syllable ID nested within bird ID as a random variable for the analyses of syllable sequencing and structure. Tukey's HSD was used for all post hoc contrasts.

\section{RESULTS}

\section{Effects of Repeated Exposures to Females on the Motivation to Produce and the Performance of Courtship Song}

To assess how familiarity affects the motivation to produce courtship song, we briefly exposed male Bengalese finches to a stimulus female on three consecutive occasions before presenting the male with a different stimulus female (" $3 \mathrm{X}$ tests"; $n=16$ males; Figure 1). We computed the proportion of presentations in which a male produced courtship song to a female as a function of the number of exposures to the female (Table 1). We observed that the proportion of presentations in which a male produced courtship song significantly decreased with repeated exposures to an individual female $\left(F_{(2,30)}=6.1, p<0.0001\right.$; Figure 2). Males produced courtship song on $60 \%, 34 \%$, and $23 \%$ of the 1 st, 2nd, and 3rd exposures to individual females, respectively (Table 1). All contrasts were significant (Tukey's HSD, $p<0.05$ ), indicating that the likelihood that a male would produce courtship song significantly decreased from the first to second, the first to third, and the second to third exposure.

Memory for individual females may also be reflected in measures of song performance. Before analyzing the effect of familiarity on song performance, we first confirmed that exposures to females changed song performance. We compared 
TABLE 1 | Number of stimulus females and number of presentations with courtship song for each male administered $3 X$ tests (i.e., male exposed to stimulus female on three consecutive occasions before switching the stimulus female).

\begin{tabular}{|c|c|c|c|c|c|c|c|}
\hline \multirow[b]{2}{*}{ Male ID } & \multirow[b]{2}{*}{$\begin{array}{c}\text { \# of } \\
\text { females }\end{array}$} & \multicolumn{2}{|c|}{ FIRST EXPOSURE } & \multicolumn{2}{|c|}{ SECOND EXPOSURE } & \multicolumn{2}{|c|}{ THIRD EXPOSURE } \\
\hline & & $\begin{array}{c}\text { \# of presentations } \\
\text { with courtship } \\
\text { song }\end{array}$ & $\begin{array}{l}\text { proportion of } \\
\text { presentations with } \\
\text { courtship song }\end{array}$ & $\begin{array}{c}\text { \# of presentations } \\
\text { with courtship } \\
\text { song }\end{array}$ & $\begin{array}{l}\text { proportion of } \\
\text { presentations with } \\
\text { courtship song }\end{array}$ & $\begin{array}{c}\text { \# of presentations } \\
\text { with courtship } \\
\text { song }\end{array}$ & $\begin{array}{l}\text { proportion of } \\
\text { presentations with } \\
\text { courtship song }\end{array}$ \\
\hline o174br12 & 6 & 4 & 0.67 & 4 & 0.67 & 3 & 0.50 \\
\hline s935 & 6 & 4 & 0.67 & 3 & 0.50 & 1 & 0.17 \\
\hline s2295 & 7 & 5 & 0.71 & 5 & 0.71 & 3 & 0.43 \\
\hline bl12w13 & 8 & 4 & 0.50 & 4 & 0.50 & 6 & 0.75 \\
\hline black & 8 & 5 & 0.63 & 3 & 0.38 & 1 & 0.13 \\
\hline o189br53 & 8 & 6 & 0.75 & 1 & 0.13 & 2 & 0.25 \\
\hline s1408g & 8 & 5 & 0.63 & 2 & 0.25 & 1 & 0.13 \\
\hline p163y48 & 8 & 3 & 0.38 & 0 & 0.00 & 0 & 0.00 \\
\hline p173y53 & 8 & 7 & 0.88 & 3 & 0.38 & 2 & 0.25 \\
\hline p183y25 & 8 & 4 & 0.50 & 1 & 0.13 & 0 & 0.00 \\
\hline bl27p163 & 8 & 3 & 0.38 & 2 & 0.25 & 1 & 0.13 \\
\hline b|93p188 & 8 & 5 & 0.63 & 3 & 0.38 & 0 & 0.00 \\
\hline p177y27 & 8 & 2 & 0.25 & 0 & 0.00 & 0 & 0.00 \\
\hline w340156 & 8 & 8 & 1.00 & 5 & 0.63 & 5 & 0.63 \\
\hline o138br52 & 10 & 4 & 0.40 & 1 & 0.10 & 1 & 0.10 \\
\hline s936 & 10 & 6 & 0.60 & 5 & 0.50 & 2 & 0.20 \\
\hline
\end{tabular}

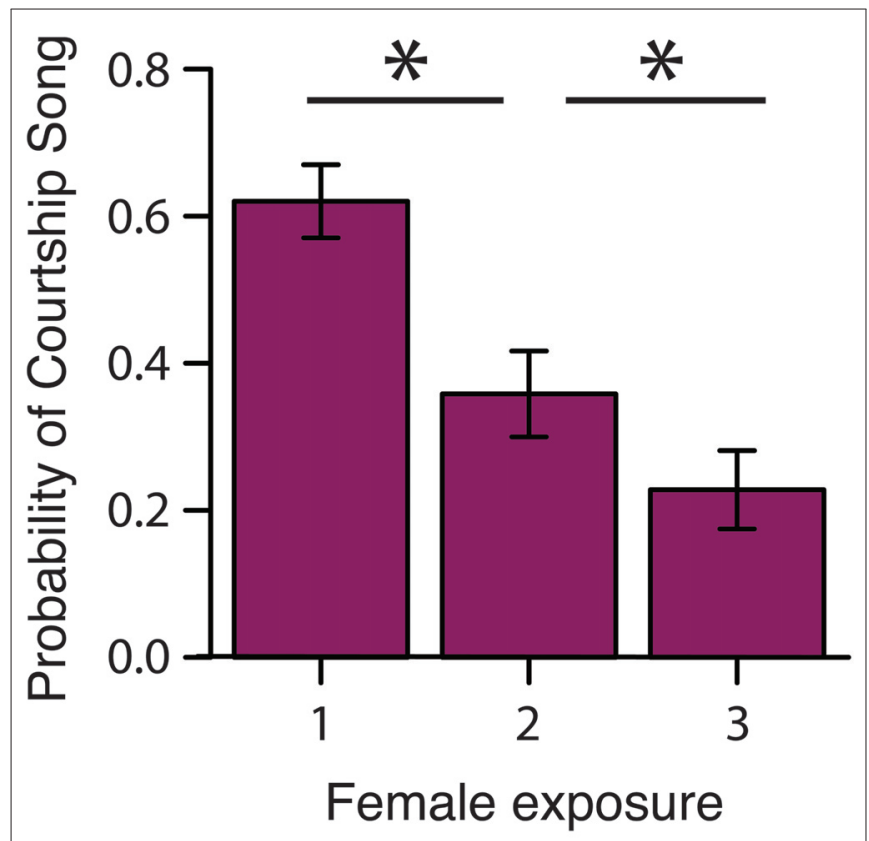

FIGURE 2 | Familiarity rapidly affects the motivation to produce courtship song. During $3 X$ tests, the probability that a male produced courtship song (i.e., proportion of presentations in which a male produced courtship song) significantly decreased from the 1st to 2nd and 2nd to 3rd exposure to a female ( $n=16$ males). ${ }^{*} p<0.05$.

the songs that males produced to females during courtship interactions ("courtship songs") and the songs that males produce when alone ("non-courtship songs") during $3 \mathrm{X}$ tests. We analyzed the songs of males that produced courtship songs on at least three presentations to stimulus females ( $n=14$ males) and analyzed, on average, $11.9 \pm 1.3$ (mean \pm SEM; range: $5-20$ ) courtship songs and $19.4 \pm 1.9$ (range: 12-35) non-courtship songs per male. Overall, we observed context-dependent changes to song that were similar to previously documented changes (e.g., Kao and Brainard, 2006; Sakata et al., 2008; Matheson et al., 2016; Figure 3A). Specifically, sequence durations were significantly shorter during courtship song than during non-courtship song $\left(F_{(1,13)}=9.3, p=0.0092\right)$, indicating that courtship song was faster than non-courtship song. Courtship songs were preceded by significantly more introductory notes $\left(F_{(1,13)}=5.1\right.$, $p=0.0412)$ and were longer in duration $\left(F_{(1,13)}=4.7\right.$, $p=0.0483$ ) than non-courtship songs. Additionally, the FF of syllables with flat, harmonic structure $(n=51$ syllables $)$ was significantly higher $\left(F_{(1,50)}=7.5, p=0.0087\right)$ and less variable $\left(F_{(1,50)}=65.0, p<0.0001\right)$ when males produced courtship songs. Whereas previous studies have documented that syllable sequencing at branch points is less variable during courtship song than non-courtship song (e.g., Sakata et al., 2008; Sakata and Brainard, 2009; Heinig et al., 2014; James and Sakata, 2015; Matheson and Sakata, 2015b; Matheson et al., 2016), transition entropy ( $n=50$ branch points) was not significantly different between the courtship and non-courtship songs of males in this study $\left(F_{(1,49)}=1.4, p=0.2388\right)$.

To assess the degree to which these measures of song performance can serve as indices of social memory, we compared the structure of courtship songs that males produced on their first exposure to individual females to courtship songs that males produced on their subsequent exposures to the same females. Because the likelihood that a male produced courtship song to an individual female significantly decreased following the first exposure, we combined the songs that each male produced on his second and third exposures to females and compared these songs to the courtship songs produced on first exposures. This allowed us to compare datasets with similar numbers of songs ( $p=0.5208)$. We analyzed the songs of males that produced at least three songs during their first exposure to females and at least three songs during all subsequent exposures to females 


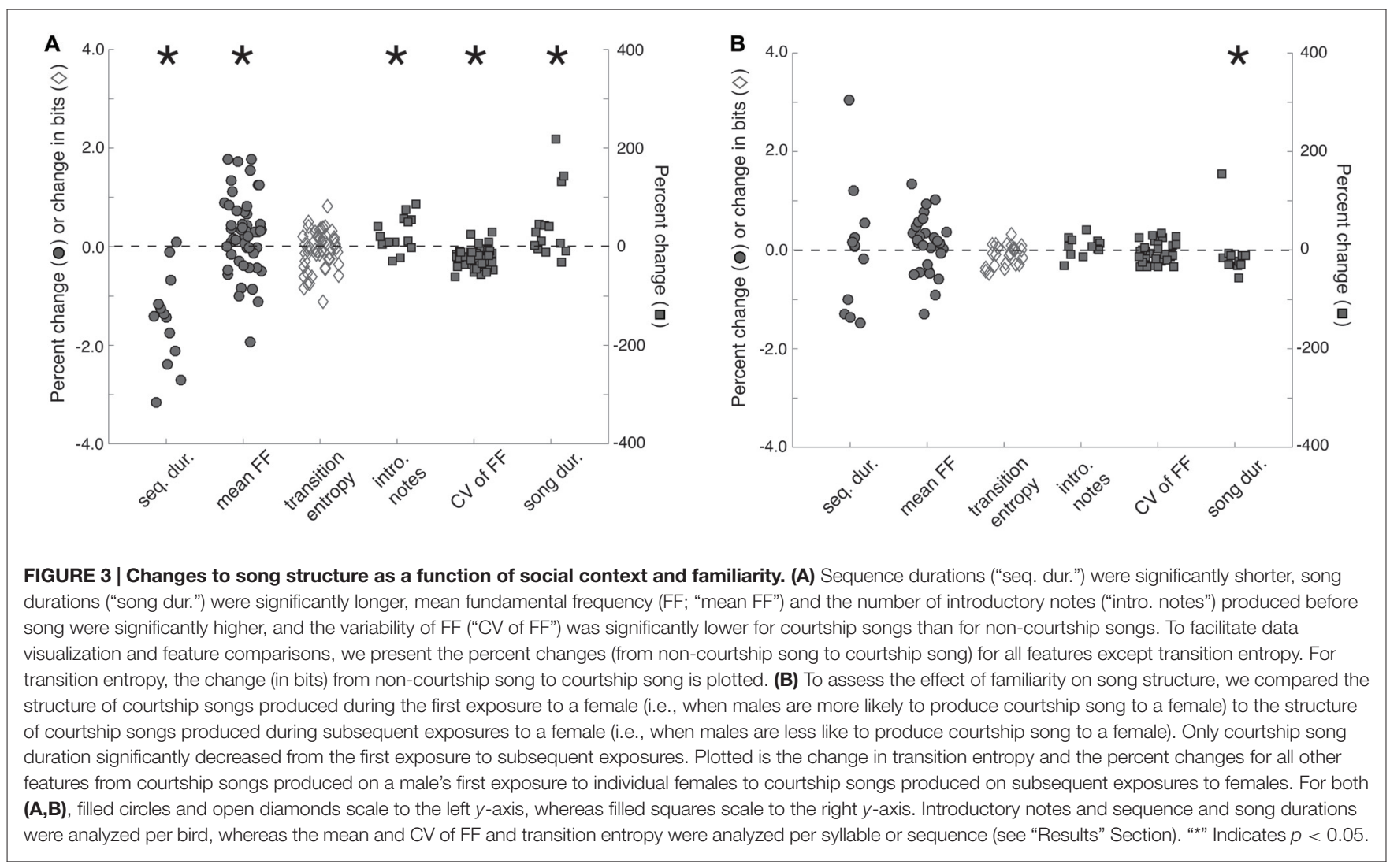

( $n=12$ males) and examined, for each male, $6.9 \pm 0.8$ (range: 4-14) courtship songs produced on first exposures and $6.0 \pm 0.9$ (range 3-10) courtship songs produced on subsequent exposures.

We found that courtship song durations on the first exposure to a female (i.e., when a male is more likely to produce courtship song to a female) were significantly longer than courtship song durations on subsequent exposures to females (i.e., when a male is less likely to produce courtship song to a female; $F_{(1,11)}=5.1, p=0.0444$; Figure 3B). However, the number of introductory notes preceding song, song tempo, the mean and variability of FF ( $n=30$ syllables), and the stereotypy of syllable sequencing ( $n=23$ branch points) were not significantly different between courtship songs produced on first and subsequent exposures to stimulus females $(p>0.05$ for all; Figure 3B).

\section{Disentangling the Effects of Social Memory and "Courtship Fatigue"}

The decrease in the production of courtship song with repeated female presentations could result from fatigue on the part of the male rather than the formation of social memories. To assess the degree to which such "courtship fatigue" contributed to the decrease in courtship song during $3 \mathrm{X}$ tests, we conducted a series of additional analyses and experiments. First, we analyzed how the likelihood of courtship song changed when we presented males with a different female after three repeated exposures to an individual female. If fatigue was the primary reason for decreases in the likelihood of courtship song during $3 \mathrm{X}$ tests, we would expect similar decreases when males were exposed to an unfamiliar female as when males were exposed to the same female on consecutive presentations. In contrast, if decreases in courtship song production were due to the formation of social memories, we would expect the likelihood of courtship song to decrease when males were consecutively exposed to the same female (i.e., habituation) and to increase when males were exposed to a different female for the first time (i.e., dishabituation).

We first analyzed changes in the proportion of males that produced courtship song across female exposures during $3 \mathrm{X}$ tests. Consistent with the notion that social memory contributes to changes in courtship song production, we found that the proportion of males producing courtship song generally decreased when males were exposed to the same female across consecutive presentations (i.e., from the first to second exposure and from the second to third exposure; Figure 4A). In addition, we observed that the proportion of males producing courtship song generally increased when males were exposed to a different female for the first time (Figure 4A). To analyze the significance of these changes, for each male we computed the change in the proportion of presentations with courtship song (i.e., the change in the likelihood that a male produced courtship song) from the first to second exposure to an individual female (" $1-2$ "), from the second to third exposure to an individual female ("2-3"), and from the third exposure to a female to the first exposure to a different female (" $3-1$ "). Changes in the likelihood 

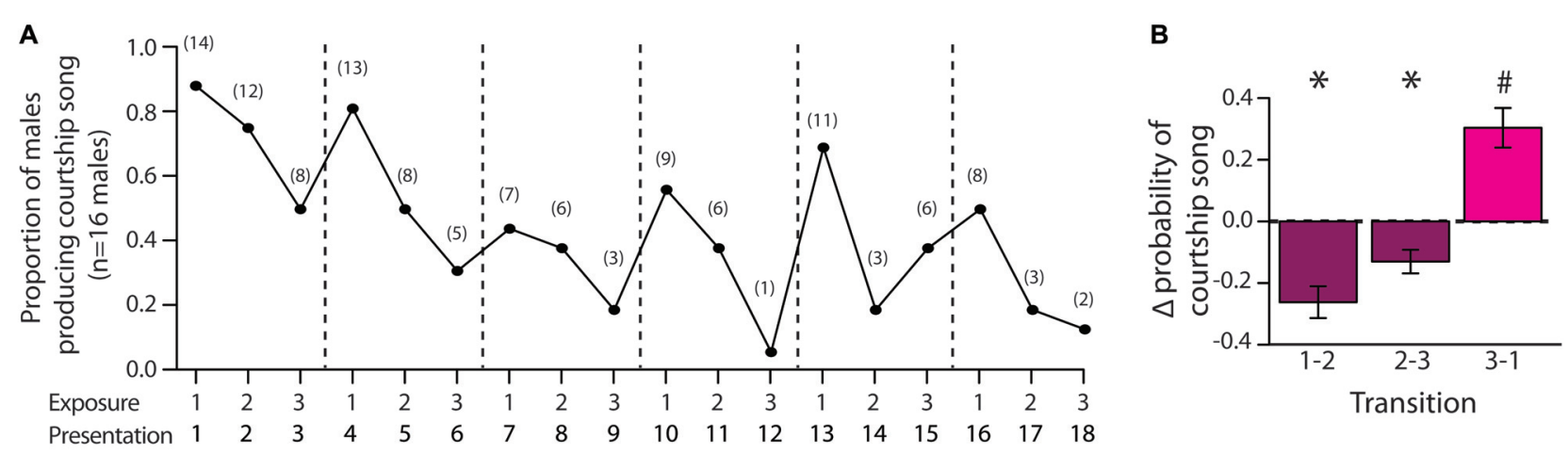

C

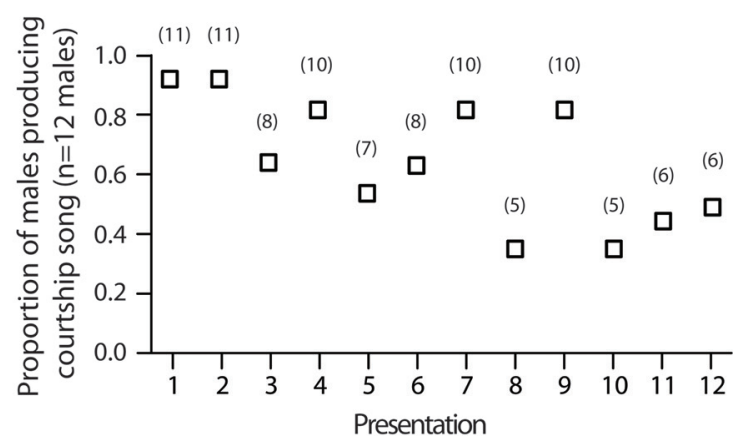

D

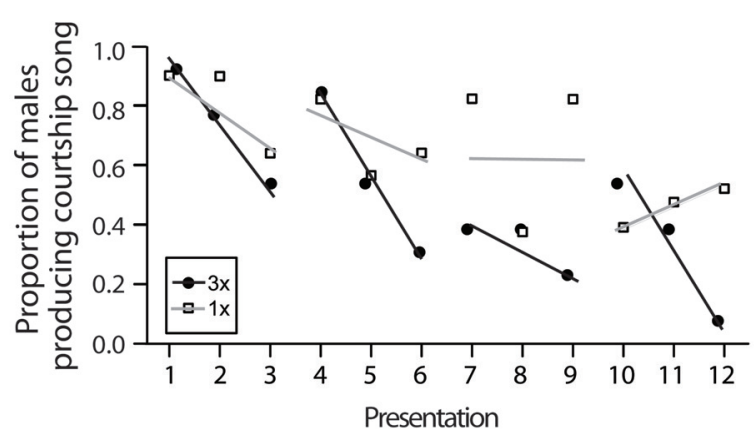

FIGURE 4 | Decreases in the production of courtship song reflect the formation of short-term memories. (A) Plotted are the proportion of male Bengalese finches $(n=16)$ that produced courtship song across each exposure to the first six stimulus females during $3 X$ tests (range: 6-10 individual females). Dashed lines indicate when the identity of the stimulus female was changed. Numbers in parentheses indicate the number of males producing courtship song for each presentation. (B) The proportion of presentations in which males produced courtship song changed in a systematic manner across exposures (3X tests). Plotted is the mean change $( \pm S E M)$ in the likelihood of courtship song (i.e., change in the proportion of presentations that an individual male produced courtship song) from the first to second exposure to a female ("1-2"), from the second to third exposure to a female ("2-3"), and from the third exposure to a female to the first exposure to a different female ("3-1"). "*” Indicates significantly less than zero $(p<0.05)$, and "\#” indicates significantly greater than zero $(p<0.05)$ and different than " $1-2$ " and "2-3". (C) The proportion of males producing courtship song to individual females gradually decreased over presentations even when the identity of the female was changed after a single exposure ( $1 X$ tests; 12 stimulus females). Numbers in parentheses indicate the number of males producing courtship song for each presentation. (D) We compared the rates of change in the proportion of males producing courtship song during $3 X$ tests, in which males were consecutively exposed to the same female (presentations 1-3, 4-6, 7-9, and 10-12; black lines), to the rates of change across the same presentations during $1 \mathrm{X}$ tests, in which males were consecutively exposed to different females (gray lines). We found that the proportion of males producing courtship song decreased at a faster rate when males were exposed to the same female across presentations than when they were exposed to different females across presentations. For this analysis, only data for males that were administered both $1 \mathrm{X}$ and $3 \mathrm{X}$ tests were examined $(n=13$ males).

of courtship song across these consecutive exposures were significantly different $\left(F_{(2,30)}=21.9, p<0.0001\right.$; Figure 4B). Specifically, the change in the likelihood of courtship song when males were exposed to a different female (i.e., from the third exposure to a female to the first exposure to a different female) was significantly more positive than the changes in the likelihood of courtship song when males were consecutively exposed to the same female (i.e., from the first to second exposure and from the second to third exposure to an individual female; Tukey's HSD, $p<0.05$ for both contrasts; Figure 4B). Furthermore, whereas changes to likelihood of courtship song were significantly negative when the female remained the same ( $t$-test; $\mathrm{H}_{0}$ : mean $=0 ; p<0.05$ for both), the change in the likelihood of courtship song was significantly positive when the stimulus female was changed ( $p=0.0028$; Figure 4B).

The previous analysis does not rule out the possibility that fatigue could contribute to some extent to changes in courtship song production over the testing session. Indeed, the proportion of males that produced courtship song on their first exposure to a female tended to decrease over the course of the entire testing session, suggesting that fatigue can affect the likelihood of courtship song over the testing period. To further assess the potential contribution of fatigue, we investigated how the proportion of males producing courtship song changed when we switched the stimulus female after single exposures (" $1 \mathrm{X}$ tests"; $n=13$ males). There was generally a linear decrease in the proportion of males producing courtship song across the 12 presentations of stimulus females $\left(F_{(1,10)}=10.3, p=0.0093\right.$; slope: $-3.7 \pm 1.1 \%$; Figure 4C).

To quantify the relative contributions of social memory and fatigue to courtship song production, we compared the rates of change in the proportion of males producing courtship song across presentations between $3 \mathrm{X}$ and $1 \mathrm{X}$ tests. All of the males given $1 \mathrm{X}$ tests were also administered $3 \mathrm{X}$ tests, allowing us 
to directly compare the rates of change in a paired manner. For both $3 \mathrm{X}$ and $1 \mathrm{X}$ tests, there was a significant negative relationship between exposure number and the proportion of males producing courtship song ( $p<0.01$ for both). However, the rate of change was steeper during $3 \mathrm{X}$ tests (slope $\pm \mathrm{SEM}$ : $-5.6 \pm 1.3 \%$ ) than during $1 \mathrm{X}$ tests (slope \pm SEM: $-3.7 \pm 1.1 \%$ ). This difference is even more striking when examining the rate of change across presentations in which females remained the same for $3 X$ tests (i.e., presentations 1-3, 4-6, 7-9, and 10-12). The average rate of change when males were exposed to the same female during $3 \mathrm{X}$ tests was $-19.2 \pm 4.0 \%$. In contrast, the average rate of change was only $-3.4 \pm 4.0 \%$ for $1 \mathrm{X}$ tests over the same ranges of presentations, and this difference between $3 \mathrm{X}$ and $1 \mathrm{X}$ tests approached significance $\left(F_{(1,3)}=9.6, p=0.0531\right.$; Figure 4D).

\section{Persistence of Social Memories Across Days}

To assess the persistence of social memories for individual females, we investigated courtship song production 2 days after initial exposures to females (e.g., 2 days after $3 \mathrm{X}$ tests; "longerterm memory tests"). We analyzed the degree to which males differentially produced courtship song to familiar females (i.e., females that males were exposed to 2 days earlier) and unfamiliar females (i.e., females that males were not exposed to 2 days earlier). Two days after $3 \mathrm{X}$ tests, male Bengalese finches $(n=13)$ were significantly less likely to produce courtship song to familiar females than to unfamiliar females $\left(F_{(1,12)}=7.0, p=0.0213\right.$; Figure 5A; Table 2). On average, males produced courtship song to familiar females on only $41.0 \pm 6.1 \%$ of presentations whereas they produced courtship song to unfamiliar females on $58.7 \pm 6.1 \%$ of presentations. This difference could be due to a decrease in courtship song production towards familiar females or to an increase in courtship song production towards unfamiliar females; therefore, we compared a male's courtship song production to familiar and unfamiliar females on longerterm tests against courtship song production during the first exposure to females during $3 \mathrm{X}$ tests. Males were significantly less likely to produce courtship song when they were exposed to familiar females during longer-term memory tests than when they were exposed to these same females for the first time during $3 \mathrm{X}$ tests $\left(F_{(1,12)}=20.3, p=0.0007\right)$. Additionally, males were as likely to produce courtship song to an unfamiliar female during longer-term memory tests as to an unfamiliar female during the $3 \mathrm{X}$ tests $\left(F_{(1,12)}=0.0, p=0.9448\right)$. Therefore, the difference in courtship song production during longer-term memory tests was due to a decrease in courtship song production to familiar females.

To assess the degree to which song performance could reflect longer-term memory for individual females, we compared various measures of song performance between courtship songs produced to familiar and to unfamiliar stimulus females 2 days after $3 \mathrm{X}$ tests. We analyzed songs only from males that produced at least three courtship songs to unfamiliar females and at least three courtship songs to familiar females $(n=7$ males), and for each male we examined, on average, $5.1 \pm 0.5$


FIGURE 5 | Repeated exposures to females are important for the persistence of social memories over days (longer-term memory tests). (A) When tested 2 days after $3 X$ tests, male Bengalese finches were significantly less likely to produce courtship song to familiar females than to unfamiliar females ( $n=13$ males; Table 2 ). Plotted are the average ( \pm SEM) proportions of presentations with courtship song. (B) Two days after $3 X$ tests, males produced shorter courtship songs to familiar females than to unfamiliar females ( $n=7$ males; i.e., only males that produced at least three courtship songs to familiar females and at least three courtship songs to unfamiliar females). (C) Two days after $1 \mathrm{X}$ tests, males did not differentially produce courtship song to unfamiliar and familiar females ( $n=7$ males). (D) Two days after $1 \mathrm{X}$ tests, males produced courtship songs to familiar and to unfamiliar females that were of similar duration ( $n=6$ males; i.e., only males that produced at least three courtship songs to familiar females and at least three courtship songs to unfamiliar females). (E) Two days after $2 X$ tests, males did not differentially produce courtship song to unfamiliar and familiar females ( $n=10$ males). (F) Two days after $2 X$ tests, males produced courtship songs to familiar and to unfamiliar females that were of similar duration $(n=8$ males; i.e., only males that produced at least three courtship songs to familiar females and at least three courtship songs to unfamiliar females). For all panels, "*” indicates $p<0.05$.

(range: 3-7) courtship songs directed at unfamiliar females and $4.6 \pm 0.6$ (range: $3-7$ ) courtship songs produced to familiar females. Courtship song durations were shorter when males 
TABLE 2 | Number of stimulus females and number and proportion of presentations with courtship song for each male during longer-term memory tests 2 days after $3 X$ tests.

\begin{tabular}{|c|c|c|c|c|c|}
\hline \multirow[b]{2}{*}{ Male ID } & \multirow[b]{2}{*}{$\begin{array}{c}\text { \# of } \\
\text { females }\end{array}$} & \multicolumn{2}{|c|}{ UNFAMILIAR FEMALES } & \multicolumn{2}{|c|}{ FAMILIAR FEMALES } \\
\hline & & $\begin{array}{c}\text { \# of presentations } \\
\text { with courtship } \\
\text { song }\end{array}$ & $\begin{array}{l}\text { proportion of } \\
\text { presentations with } \\
\text { courtship song }\end{array}$ & $\begin{array}{c}\text { \# of presentations } \\
\text { with courtship } \\
\text { song }\end{array}$ & $\begin{array}{l}\text { proportion of } \\
\text { presentations with } \\
\text { courtship song }\end{array}$ \\
\hline o174br12 & 6 & 5 & 0.83 & 3 & 0.50 \\
\hline bl12w13 & 8 & 6 & 0.75 & 5 & 0.63 \\
\hline black & 8 & 5 & 0.63 & 2 & 0.25 \\
\hline o189br53 & 8 & 2 & 0.25 & 3 & 0.38 \\
\hline s1408g & 8 & 7 & 0.88 & 4 & 0.50 \\
\hline p168y48 & 8 & 4 & 0.50 & 3 & 0.38 \\
\hline p173y53 & 8 & 6 & 0.75 & 5 & 0.63 \\
\hline p183y25 & 8 & 5 & 0.63 & 2 & 0.25 \\
\hline bl27p163 & 8 & 3 & 0.38 & 1 & 0.13 \\
\hline b|93p188 & 8 & 3 & 0.38 & 4 & 0.50 \\
\hline p177y27 & 8 & 2 & 0.25 & 1 & 0.13 \\
\hline w340156 & 8 & 5 & 0.63 & 7 & 0.88 \\
\hline o188br52 & 10 & 8 & 0.80 & 2 & 0.20 \\
\hline
\end{tabular}

For these tests, males were individually presented with unfamiliar and familiar females only once and were exposed to the same number of unfamiliar and familiar females.

produced courtship songs to familiar females than when they produced courtship songs to unfamiliar females $\left(F_{(1,6)}=16.7, p=0.0064\right.$; Figure 5B). The durations of courtship songs were shorter when males were exposed to familiar females during longer-term memory tests than when they were exposed to the same females for the first time during $3 \mathrm{X}$ tests $\left(F_{(1,6)}=17.6, p=0.0057\right)$. Additionally, the durations of courtship songs that males produced to unfamiliar females during longer-term memory tests were comparable to the durations of courtship songs that males produced to unfamiliar females during the $3 \mathrm{X}$ tests $\left(F_{(1,6)}=3.52\right.$, $p=0.1099)$.

Song tempo (i.e., sequence durations), the number of introductory notes preceding song, the mean and variability of $\mathrm{FF}$, and variability of syllable sequencing were not significantly different between courtship songs produced to familiar and to unfamiliar females ( $p>0.20$ for all analyses).

To gain insight into the amount of exposure that is required for the formation of longer-term social memories, we investigated whether males demonstrated similar differences in courtship song production after only one ( $n=7$ males) or two exposures ( $n=10$ males) to individual females. In contrast to the differential production of courtship song to unfamiliar females 2 days after $3 \mathrm{X}$ tests, males produced courtship song to familiar $(64.5 \pm 12.9 \%)$ and to unfamiliar (70.6 $\pm 10.0 \%)$ females to the same degree 2 days after $1 \mathrm{X}$ tests $\left(F_{(1,6)}=0.2, p=0.6371\right.$; Figure $\left.5 \mathrm{C}\right)$. The duration of courtship songs produced to familiar and to unfamiliar females was also not significantly different $\left(F_{(1,5)}=1.5, p=0.2710\right.$; Figure 5D).

Similarly, male Bengalese finches did not differentially produce courtship song to unfamiliar and familiar females 2 days after $2 \mathrm{X}$ tests $\left(F_{(1,9)}=2.8, p=0.1286\right.$; Figure $\left.5 \mathrm{E}\right)$, and the durations of courtship songs produced to familiar and to unfamiliar females were not significantly different $\left(F_{(1,7)}=0.0\right.$, $p=0.8490$; Figure 5F). This lack of longer-term memory was not due to a lack of a short-term memory formation. During $2 \mathrm{X}$ tests, these same males were significantly less likely to produce courtship song on the second exposure to an individual female than on their first exposure to the female 4-5 min earlier $\left(F_{(1,9)}=46.4, p<0.0001\right)$, and the magnitude of this decrease was comparable to the magnitude observed during the $3 \mathrm{X}$ tests.

\section{DISCUSSION}

A hallmark of social memory is the differential display of behavior toward familiar and unfamiliar individuals. For example, across a variety of species, males spend less time investigating, attempt fewer copulations with, and vocalize less in response to familiar females (e.g., Dewsbury, 1981; Thor and Holloway, 1982; Johnston and Rasmussen, 1984; Bluthe et al., 1990; D’Amato and Moles, 2001; Lukas et al., 2013; Schnell et al., 2014). Individual recognition also modulates female mating decisions, as females preferentially mate with males that they have observed winning aggressive interactions or mating with other females (Mennill et al., 2002; Valone and Templeton, 2002; Galef, 2008). However, little is known about the rapidity with which social familiarity affects the display of courtship behaviors like birdsong, or the degree to which social memory differentially affects different aspects of courtship behavior.

Here, we used a habituation-dishabituation assay to investigate how familiarity affected the motivation to produce courtship song and the performance of courtship song in the Bengalese finch. We document that a single, brief exposure to a female $(<30 \mathrm{~s})$ decreased the likelihood that a male would produce courtship song upon re-exposure to that same female 5 min later (i.e., habituation) and that exposing a male to a different female after repeated exposures to the same female increased the likelihood of courtship song (i.e., dishabituation). We argue that such decreases in courtship song following re-exposure to females reflect the formation of social memories for individual females and do not solely reflect fatigue on 
the part of the male. This is because the proportion of males producing courtship song decreased at a faster rate when males were exposed to the same female across consecutive presentations than when males were exposed to different females across consecutive presentations. Further, 2 days after repeated exposures to individual females, males remained less likely to produce courtship song to familiar females than to unfamiliar females, suggesting the formation of longer-term social memories. This longer-term memory for females seemed to require at least three consecutive exposures to a female, since the differential production of courtship song to unfamiliar females was observed after $3 \mathrm{X}$ tests but not after $1 \mathrm{X}$ or $2 \mathrm{X}$ tests. However, in contrast to the influence of familiarity on the motivation to produce courtship song, various measures of song performance (e.g., song tempo, syllable structure and sequencing) were not affected by social memory formation. These data reveal the persistence and rapid formation of social memories and the distinct effects of familiarity on motivational and performance aspects of courtship song.

The decrease in the production of courtship song to individual females could not only signify the formation of social memories for individual females but also represent an adaptive change in male behavior. Female responses during social interactions have been found to influence male courtship and vocal behavior in a variety of ways. For example, feedback from females modulates the intensity of courtship displays in bowerbirds and the trajectory of vocal learning in juvenile male cowbirds (West and King, 1988; Patricelli et al., 2002; Miller et al., 2008; Dohme et al., 2015). Furthermore, "rejection" behaviors by females or a lack of positive reinforcement following exposure to females can lead to a decrease in the expression of courtship or appetitive behaviors (e.g., Griffith and Ejima, 2009; Cornil and Ball, 2010). In our experiments, male Bengalese finches were denied the opportunity to copulate with stimulus females, and it is possible that males interpreted that lack of successful mating following courtship song as rejection. Consequently, the decrease in the production of courtship song could represent an adaptive response to divert reproductive effort away from females that will not allow mating opportunities. Further, while we did not notice conspicuous changes to the behavior of stimulus females across presentations, it is possible that stimulus females' behavior toward males subtly changed across repeated exposures in ways that could have influenced a male's motivation to produce courtship song.

In contrast to the rapid effects of familiarity on the motivation to produce courtship song, familiarity did not significantly influence the performance of song features that can influence the attractiveness of a male's song, including song tempo, syllable structure, or syllable sequencing (Catchpole and Slater, 2008; Sakata and Vehrencamp, 2012; Dunning et al., 2014). However, our data do not rule out the possibility that social familiarity can affect song performance. Indeed, a previous study found that the sequencing of syllables during courtship song becomes more variable (i.e., more like non-courtship song) across longer periods of exposure to females (Heinig et al., 2014). The authors housed male Bengalese finches next to individual females for one hour and found that syllable sequencing was more stereotyped for the first three courtship songs than for courtship songs produced during the remainder of the hour. The first three courtship songs were produced within minutes after the introduction of the female, whereas the courtship songs produced later in the testing period were produced, on average, over $30 \mathrm{~min}$ after the introduction of the female. In our experiment, we only briefly exposed males to females ( $<30 \mathrm{~s}$ per presentation) and generally contrasted a male's song performance during his first exposure to a female to his song performance during subsequent exposures within $10 \mathrm{~min}$ of the first exposure. Together, these studies suggest a hierarchy of influences on courtship song and that social familiarity affects the motivation to sing more rapidly than it affects the performance of song.

The circuit connecting the medial preoptic area (POM), midbrain areas like the ventral tegmental area (VTA) and periaqueductal gray (PAG), and song control nuclei is hypothesized to influence various aspects of song production, including the motivation to sing (Riters and Ball, 1999; Goodson, 2005; Bharati and Goodson, 2006; Yanagihara and Hessler, 2006; reviewed in Balthazart and Ball, 2007; Alger et al., 2009; Goodson et al., 2009; Riters, 2012). In particular, dopaminergic projections from the VTA and PAG are thought to influence the motivation to produce courtship song. This idea is supported by findings that dopaminergic neurons in these areas are more active during the production of courtship song than during the production of non-courtship song (Yanagihara and Hessler, 2006; Hara et al., 2007; Goodson et al., 2009; Matheson and Sakata, 2015a). However, dopamine from the VTA and PAG has also been found to affect the performance of song (reviewed in Woolley and Kao, 2015). Dopamine concentrations in song control nuclei such as the basal ganglia nucleus Area $\mathrm{X}$ are elevated when male songbirds produce courtship song (Sasaki et al., 2006; Ihle et al., 2015), and pharmacological manipulations that increase dopamine concentrations in the brain increase the stereotypy of syllable structure and sequencing (Matheson and Sakata, 2015a). Further, antagonism of dopamine receptors in Area X inhibits the social modulation of song structure (Leblois et al., 2010; Murugan et al., 2013). Consequently, if changes to VTA and PAG activity are central to the decrease in courtship song production following repeated exposures to females, we should similarly observe changes to various measures of song performance across repeated exposures to females. Because we did not observe changes to song performance, our findings suggest that mechanisms independent of dopamine could also contribute to changes to courtship song production that accompany social memory formation. For example, because arginine vasotocin (AVT; the non-mammalian homolog of vasopressin) influences the motivation to produce courtship vocalizations without affecting acoustic structure in species like the plainfin midshipman (e.g., Goodson and Bass, 2000, 2001; Goodson and Thompson, 2010), AVT could mediate the observed changes to courtship song production in male Bengalese finches.

Regardless of the precise neurochemical mechanisms underlying the effects of familiarity on the production of 
courtship song, our data support the notion that motivational and performance aspects of social behaviors can be dissociated (Riters and Balthazart, 1998; reviewed in Balthazart and Ball, 2007; Cornil and Ball, 2010). Our findings that repeated exposures to individual females affected the motivation to produce courtship song without affecting various measures of song performance bear striking similarity to the effects of testosterone in the POM on singing behavior in canaries (Alward et al., 2013). In canaries, testosterone implants directly into the POM increase the prevalence and duration of song but do not affect song stereotypy. Despite that testosterone exerts its effects in the POM over days whereas familiarity rapidly modulates song production over minutes, these behavioral similarities suggest that the mechanisms through which social memory affects song production in Bengalese finches could resemble the mechanisms through which testosterone in the POM affects song production in male canaries.

Taken together, our studies reveal the ability of male songbirds to rapidly form social memories of females, the importance of repeated exposures for the longer-term persistence of social memories, and the dissociable effects of

\section{REFERENCES}

Alger, S. J., Maasch, S. N., and Riters, L. V. (2009). Lesions to the medial preoptic nucleus affect immediate early gene immunolabeling in brain regions involved in song control and social behavior in male european starlings. Eur. J. Neurosci. 29, 970-982. doi: 10.1111/j.1460-9568.2009.06637.x

Alward, B. A., Balthazart, J., and Ball, G. F. (2013). Differential effects of global versus local testosterone on singing behavior and its underlying neural substrate. Proc. Natl. Acad. Sci. U S A 110, 19573-19578. doi: 10.1073/pnas. 1311371110

Balthazart, J., and Ball, G. F. (2007). Topography in the preoptic region: differential regulation of appetitive and consummatory male sexual behaviors. Front. Neuroendocrinol. 28, 161-178. doi: 10.1016/j.yfrne.2007.05.003

Bertram, R., Daou, A., Hyson, R. L., Johnson, F., and Wu, W. (2014). Two neural streams, one voice: pathways for theme and variation in the songbird brain. Neuroscience 277, 806-817. doi: 10.1016/j.neuroscience.2014.07.061

Bharati, I. S., and Goodson, J. L. (2006). Fos responses of dopamine neurons to sociosexual stimuli in male zebra finches. Neuroscience 143, 661-670. doi: 10. 1016/j.neuroscience.2006.08.046

Blocker, T. D., and Ophir, A. G. (2015). Social recognition in paired, but not single, male prairie voles. Anim. Behav. 108, 1-8. doi: 10.1016/j.anbehav.2015.07.003

Bluthe, R. M., Schoenen, J., and Dantzer, R. (1990). Androgen-dependent vasopressinergic neurons are involved in social recognition in rats. Brain Res. 519, 150-157. doi: 10.1016/0006-8993(90)90073-k

Bolhuis, J. J., Okanoya, K., and Scharff, C. (2010). Twitter evolution: converging mechanisms in birdsong and human speech. Nat. Rev. Neurosci. 11, 747-759. doi: $10.1038 / \mathrm{nrn} 2931$

Bradbury, J. W., and Vehrencamp, S. L. (2011). Principles of Animal Communication, 2nd Edn. (Sunderland, UK: Sinauer Associates).

Brainard, M. S., and Doupe, A. J. (2013). Translating birdsong: songbirds as a model for basic and applied medical research. Annu. Rev. Neurosci. 36, 489-517. doi: 10.1146/annurev-neuro-060909-152826

Catchpole, C. K., and Slater, P. J. B. (2008). Bird Song: Biological Themes and Variations, 2nd Edn. (New York, NY: Cambridge University Press).

Caryl, P. G. (1976). Sexual behaviour in the zebra finch taeniopygia guttata: response to familiar and novel partners. Anim. Behav. 24, 93-107. doi: 10 . 1016/s0003-3472(76)80103-0

Chi, Z., and Margoliash, D. (2001). Temporal precision and temporal drift in brain and behavior of zebra finch song. Neuron 32, 899-910. doi: 10.1016/s08966273(01)00524-4 familiarity on motivation and performance. These data highlight the role of cognitive processes in social behavioral expression and motivate further investigations into the neurochemical systems that underlie the formation of short- and longer-term social memories.

\section{AUTHOR CONTRIBUTIONS}

DCT helped design experiments, collect and analyze data, write manuscript. HS helped design experiments, analyze data, write manuscript. JTS helped design experiments, analyze data, write manuscripts.

\section{ACKNOWLEDGMENTS}

We would like to thank L.E. Matheson, Y. Chen, L.S. James, A.M.M. Matheson, J.P. Britt, and S.C. Woolley for assistance with data collection, analysis, and manuscript preparation. Research was supported by funding from the Natural Sciences and Engineering Research Council (JTS: 402417-11), the Center for Studies in Behavioral Neurobiology, and McGill University.

Cooper, B. G., and Goller, F. (2006). Physiological insights into the social-contextdependent changes in the rhythm of the song motor program. J. Neurophysiol. 95, 3798-3809. doi: 10.1152/jn.01123.2005

Cooper, B. G., Mendez, J. M., Saar, S., Whetstone, A. G., Meyers, R., and Goller, F. (2012). Age-related changes in the bengalese finch song motor program. Neurobiol. Aging. 33, 564-568. doi: 10.1016/j.neurobiolaging.2010. 04.014

Cornil, C. A., and Ball, G. F. (2010). Effects of social experience on subsequent sexual performance in naïve male japanese quail (coturnix japonica). Horm. Behav. 57, 515-522. doi: 10.1016/j.yhbeh.2010.02.010

D'Amato, F. R. (1997). Neurobiological and behavioural aspects of recognition in female mice. Physiol. Behav. 62, 1311-1317. doi: 10.1016/s00319384(97)00343-0

D'Amato, F. R., and Moles, A. (2001). Ultrasonic vocalizations as an index of social memory in female mice. Behav. Neurosci. 115, 834-840. doi: 10.1037/07357044.115.4.834

de Cheveigné, A., and Kawahara, H. (2002). YIN, a fundamental frequency estimator for speech and music. J. Acoust. Soc. Am. 111, 1917-1930. doi: 10. $1121 / 1.1458024$

Dewsbury, D. A. (1979). Copulatory behavior of deer mice (Peromyscus maniculatus): II. A study of some factors regulating the fine structure of behavior. J.Comp. Phys. Psychol. 93, 161-177. doi: 10.1037/h0077574

Dewsbury, D. A. (1981). Effects of novelty on copulatory behaviour: the coolidge effect and related phenomena. Psychol. Bull. 89, 464-482. doi: 10.1037/00332909.89.3.464

Dohme, R., King, A. P., Meredith, G. R., and West, M. J. (2015). Is female visual signaling to male song socially regulated in brown-headed cowbirds? Ethology 121, 327-334. doi: 10.1111/eth.12341

Dong, S., and Clayton, D. F. (2009). Habituation in songbirds. Neurobiol. Learn. Mem. 92, 183-188. doi: 10.1016/j.nlm.2008.09.009

Dunning, J. L., Pant, S., Bass, A., Coburn, Z., and Prather, J. F. (2014). Mate choice in adult female Bengalese finches: females express consistent preferences for individual males and prefer female-directed song performances. PLoS One 9:e89438. doi: 10.1371/journal.pone.0089438

Erickson, C. J., and Morris, R. L. (1972). Effects of mate familiarity on the courtship and reproductive success of the ring dove (streptopelia risoria). Anim. Behav. $20,341-344$

Fujimoto, H., Hasegawa, T., and Watanabe, D. (2011). Neural coding of syntactic structure in learned vocalizations in the songbird. J. Neurosci. 31, 10023-10033. doi: 10.1523/jneurosci.1606-11.2011 
Galef, B. G. (2008). Social influences on the mate choices of male and female Japanese quail. Comp. Cogn. Behav. Rev. 3, 1-12. doi: 10.3819/ccbr.2008.30001

Glaze, C. M., and Troyer, T. W. (2006). Temporal structure in zebra finch song: implications for motor coding. J. Neurosci. 26, 991-1005. doi: 10. 1523/jneurosci.3387-05.2006

Goodson, J. L. (2005). The vertebrate social behavior network: evolutionary themes and variations. Horm. Behav. 48, 11-22. doi: 10.1016/j.yhbeh.2005.02.003

Goodson, J. L., and Bass, A. H. (2000). Vasotocin innervation and modulation of vocal-acoustic circuitry in the teleost Porichthys notatus. J. Comp. Neurol. 422, 363-379. doi: 10.1002/1096-9861(20000703)422:3<363::aid-cne4>3.0.co;2-8

Goodson, J. L., and Bass, A. H. (2001). Social behavior functions and related anatomical characteristics of vasotocin/vasopressin systems in vertebrates. Brain Res. Brain Res. Rev. 35, 246-265. doi: 10.1016/s0165-0173(01)00065-0

Goodson, J. L., and Thompson, R. R. (2010). Nonapeptide mechanisms of social cognition, behavior and species-specific social systems. Curr. Opin. Neurobiol. 20, 784-794. doi: 10.1016/j.conb.2010.08.020

Goodson, J. L., Kabelik, D., Kelly, A. M., Rinaldi, J., and Klatt, J. D. (2009). Midbrain dopamine neurons reflect affiliation phenotypes in finches and are tightly coupled to courtship. Proc. Natl. Acad. Sci. U S A 106, 8737-8742. doi: $10.1073 /$ pnas.0811821106

Gotelli, N. J., and Ellison, M. (2013). A Primer of Ecological Statistics, 2nd Edn. (Sunderland, MA: Sinauer).

Grabowska-Zhang, A. M., Sheldon, B. C., and Hinde, C. A. (2012). Long-term familiarity promotes joining in neighbour nest defence. Biol. Lett. 8, 544-546. doi: $10.1098 / \mathrm{rsbl} .2012 .0183$

Griffith, L. C., and Ejima, A. (2009). Courtship learning in Drosophila melanogaster: diverse plasticity of a reproductive behavior. Learn. Mem. 16, 743-750. doi: 10.1101/lm.956309

Guan, X., and Dluzen, D. E. (1994). Age related changes of social memory/recognition in male fischer 344 rats. Behav. Brain Res. 61, 87-90. doi: 10.1016/0166-4328(94)90011-6

Hampton, C. M., Sakata, J. T., and Brainard, M. S. (2009). An avian basal gangliaforebrain circuit contributes differentially to syllable versus sequence variability of adult Bengalese finch song. J. Neurophysiol. 101, 3235-3245. doi: 10.1152/jn. 91089.2008

Hara, E., Kubikova, L., Hessler, N. A., and Jarvis, E. D. (2007). Role of the midbrain dopaminergic system in modulation of vocal brain activation by social context. Eur. J. Neurosci. 25, 3406-3416. doi: 10.1111/j.1460-9568.2007.05600.x

Heinig, A., Pant, S., Dunning, J., Bass, A., Coburn, Z., and Prather, J. F. (2014). Male mate preferences in mutual mate choice: finches modulate their songs across and within male-female interactions. Anim. Behav. 97, 1-12. doi: 10 . 1016/j.anbehav.2014.08.016

Hilliard, S., Nguyen, M., and Domjan, M. (1997). One-trial appetitive conditioning in the sexual behavior system. Psychon. Bull. Rev. 4, 237-241. doi: 10. 3758/BF03209399

Horn, G. (2004). Pathways of the past: the imprint of memory. Nat. Rev. Neurosci. 5, 108-120. doi: 10.1038/nrn1324

Ihle, M., Kempenaers, B., and Forstmeier, W. (2015). Fitness benefits of mate choice for compatibility in a socially monogamous species. PLoS Biol. 13:e1002248. doi: 10.1371/journal.pbio.1002248

Insel, T. R., and Fernald, R. D. (2004). How the brain processes social information: searching for the social brain. Annu. Rev. Neurosci. 27, 697-722. doi: 10. 1146/annurev.neuro.27.070203.144148

Iwasaki, M., Poulsen, T. M., Oka, K., and Hessler, N. A. (2013). Singing-related activity in anterior forebrain of male zebra finches reflects courtship motivation for target females. PloS One 8:e81725. doi: 10.1371/journal.pone.0081725

James, L. S., and Sakata, J. T. (2014). Vocal motor changes beyond the sensitive period for song plasticity. J. Neurophysiol. 112, 2040-2052. doi: 10.1152/jn. 00217.2014

James, L. S., and Sakata, J. T. (2015). Predicting plasticity: acute context-dependent changes to vocal performance predict long-term age-dependent changes. J. Neurophysiol. 114, 2328-2339. doi: 10.1152/jn.00688.2015

Jaška, P., Linhart, P., and Fuchs, R. (2015). Neighbour recognition in two sister songbird species with a simple and complex repertoire-a playback study. J. Avian. Biol. 46, 151-158. doi: 10.1111/jav.00482

Johnston, R. E., and Rasmussen, K. (1984). Individual recognition of female hamsters by males: role of chemical cues and of the olfactory and vomeronasal systems. Physiol. Behav. 33, 95-104. doi: 10.1016/0031-9384(84)90019-2
Kakishita, Y., Sasahara, K., Nishino, T., Takahashi, M., and Okanoya, K. (2008). Ethological data mining: an automata-based approach to extract behavioral units and rules. Data Min. Knowl. Discov. 18, 446-471. doi: 10.1007/s10618008-0122-1

Kao, M. H., and Brainard, M. S. (2006). Lesions of an avian basal ganglia circuit prevent context-dependent changes to song variability. J. Neurophysiol. 96, 1441-1455. doi: 10.1152/jn.01138.2005

Leblois, A., Wendel, B. J., and Perkel, D. J. (2010). Striatal dopamine modulates basal ganglia output and regulates social context-dependent behavioral variability through D1 receptors. J. Neurosci. 30, 5730-5743. doi: 10. 1523/jneurosci.5974-09.2010

Lukas, M., Toth, I., Veenema, A. H., and Neumann, I. D. (2013). Oxytocin mediates rodent social memory within the lateral septum and the medial amygdala depending on the relevance of the social stimulus: male juvenile versus female adult conspecifics. Psychoneuroendocrinology 38, 916-926. doi: 10.1016/j.psyneuen.2012.09.018

Matheson, L. E., and Sakata, J. T. (2015a). Catecholaminergic contributions to vocal communication signals. Eur. J. Neurosci. 41, 1180-1194. doi: 10.1111/ejn. 12885

Matheson, A. M., and Sakata, J. T. (2015b). Relationship between the sequencing and timing of vocal motor elements in birdsong. PLoS One 10:e0143203. doi: 10. 1371/journal.pone.0143203

Matheson, L. E., Sun, H., and Sakata, J. T. (2016). Forebrain circuits underlying the social modulation of vocal communication signals. Dev. Neurobiol 76, 47-53. doi: $10.1002 /$ dneu.22298

McCabe, B. J., and Horn, G. (1994). Learning-related changes in Fos-like immunoreactivity in the chick forebrain after imprinting. Proc. Natl. Acad. Sci. U S A 91, 11417-11421. doi: 10.1073/pnas.91.24.11417

Mennill, D. J., Ratcliffe, L. M., and Boag, P. T. (2002). Female eavesdropping on male song contests in songbirds. Science 296, 873-873. doi: 10.1126/science. 296.5569 .873

Miller, D. B. (1979). The acoustic basis of mate recognition by female zebra finches (Taeniopygia guttata). Anim. Behav. 27, 376-380.

Miller, J. L., King, A. P., and West, M. J. (2008). Female social networks influence male vocal development in brown-headed cowbirds, Molothrus ater. Anim. Behav. 76, 931-941. doi: 10.1016/j.anbehav.2008. 05.011

Moles, A., Costantini, F., Garbugino, L., Zanettini, C., and D’Amato, F. R. (2007). Ultrasonic vocalizations emitted during dyadic interactions in female mice: a possible index of sociability? Behav. Brain Res. 182, 223-230. doi: 10.1016/j. bbr.2007.01.020

Mooney, R. (2009). Neurobiology of song learning. Curr. Opin. Neurobiol 19, 654-660. doi: 10.1016/j.conb.2009.10.004

Morris, D. (1954). The reproductive behaviour of the zebra finch (Poephila guttata), with special reference to pseudofemale behaviour and displacement activities. Behaviour 6, 271-322. doi: 10.1163/156853954x 00130

Murugan, M., Harward, S., Scharff, C., and Mooney, R. (2013). Diminished FoxP2 levels affect dopaminergic modulation of corticostriatal signaling important to song variability. Neuron 80, 1464-1476. doi: 10.1016/j.neuron.2013. 09.021

Musolf, K., Hoffmann, F., and Penn, D. J. (2010). Ultrasonic courtship vocalizations in wild house mice, Mus musculus musculus. Anim. Behav. 79, 757-764. doi: 10.1016/j.anbehav.2009.12.034

Nishizawa, K., Izawa, E. I., and Watanabe, S. (2011). Neural-activity mapping of memory-based dominance in the crow: neural networks integrating individual discrimination and social behaviour control. Neuroscience 197, 307-319. doi: 10.1016/j.neuroscience.2011.09.001

O'Loghlen, A. L., and Beecher, M. D. (1999). Mate, neighbour and stranger songs: a female song sparrow perspective. Anim. Behav 58, 13-20. doi: 10.1006/anbe. 1999.1125

Okanoya, K., and Yamaguchi, A. (1997). Adult bengalese finches (Lonchura striata var. domestica) require real-time auditory feedback to produce normal song syntax. J. Neurobiol. 33, 343-356. doi: 10.1002/(SICI)10974695(199710)33:4<343::AID-NEU1>3.0.CO;2-A

Ophir, A. G., and Galef, B. G. (2004). Sexual experience can affect use of public information in mate choice. Anim. Behav 68, 1221-1227. doi: 10.1016/j. anbehav.2003.12.023 
Patricelli, G. L., Albert, J., Uy, J. A. C., Walsh, G., and Borgia, G. (2002). Male displays adjusted to female's response. Nature 415, 279-280. doi: 10. $1038 / 415279$ a

Perna, J. C., Wotjak, C. T., Stork, O., and Engelmann, M. (2015). Timing of presentation and nature of stimuli determine retroactive interference with social recognition memory in mice. Physiol. Behav. 143, 10-14. doi: 10.1016/j. physbeh.2015.02.029

Riters, L. V. (2012). The role of motivation and reward neural systems in vocal communication in songbirds. Front. Neuroendocrinol. 33, 194-209. doi: 10. 1016/j.yfrne.2012.04.002

Riters, L. V., and Ball, G. F. (1999). Lesions to the medial preoptic area affect singing in the male European starling (Sturnus vulgaris). Horm. Behav. 36, $276-286$.

Riters, L. V., and Balthazart, J. (1998). Behavioral evidence for individual recognition in Japanese quail. Behaviour 135, 551-578. doi: 10. $1163 / 156853998792897941$

Sakata, J. T., and Brainard, M. S. (2009). Social context rapidly modulates the influence of auditory feedback on avian vocal motor control. J. Neurophysiol. 102, 2485-2497. doi: 10.1152/jn.00340.2009

Sakata, J. T., Gonzalez-Lima, F., Gupta, A., and Crews, D. (2002). Repeated interactions with females elevate metabolic capacity in the limbic system of male rats. Brain Res. 936, 27-37. doi: 10.1016/s0006-8993(02)02491-5

Sakata, J. T., Hampton, C. M., and Brainard, M. S. (2008). Social modulation of sequence and syllable variability in adult birdsong. J. Neurophysiol. 99, 1700-1711. doi: 10.1152/jn.01296.2007

Sakata, J. T., and Vehrencamp, S. L. (2012). Integrating perspectives on vocal performance and consistency. J. Exp. Biol. 215, 201-209. doi: 10.1242/jeb. 056911

Sasaki, A., Sotnikova, T. D., Gainetdinov, R. R., and Jarvis, E. D. (2006). Social context-dependent singing-regulated dopamine. J. Neurosci. 26, 9010-9014. doi: 10.1523/jneurosci.1335-06.2006

Schlupp, I., Marler, C., and Ryan, M. J. (1994). Benefit to male sailfin mollies of mating with heterospecific females. Science. 263, 373-374. doi: 10.1126/science. 8278809

Schnell, A. K., Smith, C. L., Hanlon, R. T., and Harcourt, R. T. (2014). Female receptivity, mating history and familiarity influence the mating behavior of cuttlefish. Behav. Ecol. Sociobiol. 69, 283-292. doi: 10.1007/s00265-0141841-5

Stoddard, P. K., Beecher, M. D., Horning, C. L., and Campbell, S. E. (1991). Recognition of individual neighbors by song in the song sparrow, a species with song repertoires. Behav. Ecol. Sociobiol. 29, 211-215. doi: 10.1007/bf00166403

Tan, C. K., Løvlie, H., Greenway, E., Goodwin, S. F., Pizzari, T., and Wigby, S. (2013). Sex-specific responses to sexual familiarity and the role of olfaction in Drosophila. Proc. Biol. Sci. 280:20131691. doi: 10.1098/rspb.2013.1691

Temeles, E. J. (1994). The role of neighbours in territorial systems: when are they 'dear enemies'? Anim. Behav. 47, 339-350. doi: 10.1006/anbe.1994.1047

Thor, D., and Holloway, W. (1982). Social memory of the male laboratory rat. J. Comp. Phys. Psych. 96, 1000-1006. doi: 10.1037/0735-7036.96.6.1000

Town, S. M., and McCabe, B. J. (2011). Neuronal plasticity and multisensory integration in filial imprinting. PLoS One 6:e17777. doi: 10.1371/journal.pone. 0017777
Valone, T. J., and Templeton, J. J. (2002). Public information for the assessment of quality: a widespread social phenomenon. Philos. Trans. R. Soc. Lond. B Biol. Sci. 357, 1549-1557. doi: 10.1098/rstb.2002.1064

Vignal, C., Mathevon, N., and Mottin, S. (2008). Mate recognition by female zebra finch: analysis of individuality in male call and first investigations on female decoding process. Behav. Processes 77, 191-198. doi: 10.1016/j.beproc.2007. 09.003

Warren, T. L., Charlesworth, J. D., Tumer, E. C., and Brainard, M. S. (2012). Variable sequencing is actively maintained in a well learned motor skill. J. Neurosci. 32, 15414-15425. doi: 10.1523/jneurosci.1254-12.2012

West, M. J., and King, A. P. (1988). Female visual displays affect the development of male song in the cowbird. Nature 334, 244-246. doi: 10.1038/33 $4244 \mathrm{a} 0$

White, D. J. (2004). Influences of social learning on mate-choice decisions. Learn Behav. 32, 105-113. doi: 10.3758/bf03196011

Wilson, J. R., Kuehn, R. E., and Beach, F. A. (1963). Modification in the sexual behavior of male rats produced by changing the stimulus female. J. Comp. Phys. Psych. 56, 636-644. doi: 10.1037/h0042469

Woolley, S. C., and Doupe, A. J. (2008). Social context-induced song variation affects female behavior and gene expression. PLoS Biol. 6:e62. doi: 10 1371/journal.pbio.0060062

Woolley, S. C., and Kao, M. H. (2015). Variability in action: contributions of a songbird cortical-basal ganglia circuit to vocal motor learning and control. Neuroscience 296, 39-47. doi: 10.1016/j.neuroscience.2014. 10.010

Woolley, S. C., Rajan, R., Joshua, M., and Doupe, A. J. (2014). Emergence of context dependent variability across a basal ganglia network. Neuron 82 , 208-223. doi: 10.1016/j.neuron.2014.01.039

Yanagihara, S., and Hessler, N. A. (2006). Modulation of singing-related activity in the songbird ventral tegmental area by social context. Eur. J. Neurosci. 24, 3619-3627. doi: 10.1111/j.1460-9568.2006.05228.x

Young, K. A., Liu, Y., and Wang, Z. (2008). The neurobiology of social attachment: a comparative approach to behavioral, neuroanatomical and neurochemical studies. Comp. Biochem. Physiol. C. Toxicol. Pharmacol. 148, 401-410. doi: 10. 1016/j.cbpc.2008.02.004

Young, L. J., and Wang, Z. X. (2004). The neurobiology of pair bonding. Nat. Neurosci. 7, 1048-1054. doi: 10.1038/nn1327

Zann, R. A. (1996). The Zebra Finch: A Synthesis of Field and Laboratory Studies. Oxford: Oxford University Press.

Conflict of Interest Statement: The authors declare that the research was conducted in the absence of any commercial or financial relationships that could be construed as a potential conflict of interest.

Copyright (c) 2016 Toccalino, Sun and Sakata. This is an open-access article distributed under the terms of the Creative Commons Attribution License (CC BY). The use, distribution and reproduction in other forums is permitted, provided the original author(s) or licensor are credited and that the original publication in this journal is cited, in accordance with accepted academic practice. No use, distribution or reproduction is permitted which does not comply with these terms. 